\title{
CÁlCIO E SILÍCIO NA PRODUÇÃO E QUALIDADE DE SEMENTES DE SOJA ${ }^{1}$
}

\author{
FABIO SCHAUN HARTER², ANTONIO CARLOS SOUZA ALBUQUERQUE BARROS ${ }^{3}$
}

\begin{abstract}
RESUMO - A utilização de produtos naturais na proteção de plantas constitui-se em uma ferramenta importante para o agricultor de produção orgânica. O trabalho foi realizado com objetivo de avaliar a eficiência da aplicação de cálcio e silício na produção e qualidade das sementes de soja. Foram utilizadas sementes de soja orgânica (Glycine max L.) cultivar BR36, proveniente dessa cooperativa, na safra 2004/2005. O modelo experimental utilizado foi de blocos inteiramente casualizado, com cinco tratamentos (cálcio 40, cálcio 50, silício 40, silício 50 e testemunha). Os tratamentos foram comparados pelo teste de Duncan, $5 \%$ de probabilidade. As variáveis dos componentes de produção foram: número de vagens por planta, número de sementes por vagem, produtividade e rendimento de grãos. A qualidade fisiológica das sementes foi determinada pelos testes: germinação, primeira contagem de germinação, frio, condutividade elétrica e envelhecimento acelerado. Conclui-se que plantas de soja tratadas com cálcio e silício produzem sementes de maior qualidade fisiológica; os tratamentos com aplicação de $\mathrm{Ca}$ e $\mathrm{Si}$ reduzem o rendimento de sementes por unidade de área.
\end{abstract}

Termos de indexação: germinação, vigor.

\section{CALCIUM AND SILICON ON PRODUCTION AND QUALITY OF SOYBEAN SEEDS}

\begin{abstract}
The use of natural products in plant protection constitutes an important tool for the farmers to organic production. The study aimed to evaluate the efficiency of the calcium and silicon in the production and quality of soybean seeds. We used seeds of organic soybeans (Glycine $\max$ L.) cultivar BR36, from such cooperative in the 2004/2005 harvest. The experimental design used was randomized blocks with five treatments (calcium 40, calcium 50, silicon 40, silicon 50 and control). The treatments were compared by Duncan test at $5 \%$ probability. The variables of yield components were: number of pods per plant, seed number per pod, productivity and yield. The physiological quality of seeds was determined by tests: germination, first count germination, cold test, electrical conductivity and accelerated aging. Conclude that soybean plants treated with calcium and silicon produce seeds of higher physiological quality; treatments with application of $\mathrm{Ca}$ and $\mathrm{Si}$ reduce the seed yield per unit area.
\end{abstract}

Index terms: germination, vigor.

${ }^{1}$ Submetido em 17/02/2010. Aceito para publicação em 27/09/2010. Parte da dissertação do primeiro autor apresentada à UFPel.

${ }^{2}$ Eng. Agr., Doutorando, Programa de Pós-Graduação C\&T de Sementes

- FAEM/UFPel, Pelotas, RS, e-mail: fabiosharter@yahoo.com.br
${ }^{3}$ Eng. Agr., Dr., Professor Titular, Programa de Pós-Graduação C\&T de Sementes - FAEM/UFPel, Pelotas, RS, Bolsista do CNPq, e-mail: acbarros@ufepel.edu.br. 


\section{INTRODUÇÃO}

A área total de soja cultivada no Brasil, na safra 2009/10, está estimada em 47,34 milhões de hectares, com aumento de área de 7,4\%. A produção está estimada em 68,71 milhões de toneladas, é $20,2 \%$ superior da safra anterior (CONAB, 2010).

A crescente preocupação da humanidade com a insegurança gerada pelo consumo de produtos transgênicos e o uso indiscriminado de agrotóxicos no combate aos fatores limitantes ao rendimento das culturas, como doenças, pragas e plantas invasoras, acarretou um aumento na demanda mundial de pessoas interessadas em consumir alimentos mais saudáveis, oriundos da produção orgânica. Assim sendo, no Brasil o Ministério da Agricultura, Pecuária e Abastecimento, considerando esta situação, estabeleceu as normas de produção, tipificação, processamento, envase, distribuição, identificação e de certificação de qualidade para produtos orgânicos de origem vegetal e animal, conforme a Instrução Normativa $\mathrm{N}^{\circ} 7$ de 17 de maio de 1999 do Ministério da Agricultura, Pecuária e Abastecimento.

Ainda que no país o consumo de produtos orgânicos não esteja muito difundido, a área cultivada dentro deste sistema vem ganhando espaço, pois, como o Brasil é um grande exportador de alimentos não industrializados, a produção atende principalmente o mercado internacional, que cresce $20 \%$ a $30 \%$ ao ano. O cultivo da soja orgânica para consumo humano é uma alternativa para pequenos produtores. $\mathrm{O}$ consumo para alimentação humana deve crescer $300 \%$ nos próximos cinco anos. Essa alta está sendo provocada pelas descobertas das pesquisas que identificam no grão substâncias que combatem certos tipos de cânceres, osteoporoses e outras doenças. A demanda pode ser uma oportunidade para pequenos produtores terem na soja uma alternativa de renda (Ambientebrasil, 2005).

A soja orgânica, cultivada livre de produtos químicos como: herbicidas, fungicidas e inseticidas, também é um bom investimento para pequenos produtores, em média paga-se $50 \%$ mais caro pela soja orgânica frente à soja convencional (Planeta orgânico, 2010).

A Embrapa Soja (2002) vem estudando o comportamento de vários insetos-pragas para desenvolver alternativas de controle. Uma das mais conhecidas é o controle da lagarta da soja com o baculovírus, um inseticida natural elaborado a partir da própria lagarta. Outra praga cujo controle biológico foi desenvolvido pela
Embrapa Soja é a vespinha Trissolcus basalis, inimigo natural do percevejo da soja e muito eficaz nas regiões de microbacias.

Outra alternativa que vem sendo utilizada na produção orgânica é a tecnologia de filme de partícula hidrofóbica, que segundo Glenn et al. (2005), representa a síntese combinada de conhecimentos no uso de filmes hidrofóbicos, barreiras de partículas físicas e superfícies reflexivas brancas, para suprimir pragas e doenças de colheitas agrícolas. O filme de partícula hidrofóbica está baseado em um mineral inerte, que misturado com água e aplicado sob a superfície das plantas funciona como repelente. Foi mostrado que em árvores frutíferas ocorre importante supressão de pragas ao se aplicar esse produto. Além disso, o movimento do inseto alimentandose e outras atividades físicas podem ser prejudicadas severamente pela aderência de partículas ao corpo dos artrópodes, por eles rastejarem sobre o filme. Doenças podem ser prevenidas envolvendo a planta em uma partícula hidrofóbica, formando barreiras que previnem inóculo de doenças e evitam o contato da água diretamente na superfície da folha. Assim, muitos fungos e patógenos bacterianos que requerem um filme líquido de água para germinação e propagação de doenças são prevenidos. Outras características do filme de partícula hidrofóbica são que reduzem a tensão de calor, refletindo luz solar devido a sua cor branca, não afetando a fotossíntese por causa da natureza porosa do filme.

Segundo Puterka (2005), co-inventor da tecnologia de filme de partícula patenteada para insetos e controle de doenças é cobrir plantas com um protetor (barreira mineral), que previne ovoposição e alimentação das pragas.

Dentre os minerais utilizados na tecnologia de filme de partícula hidrofóbica, destaca-se o cálcio $(\mathrm{Ca})$ e o silício (Si) que além de formarem a barreira branca, são absorvidos e possuem funções fisiológicas no desenvolvimento da planta. Para o cálcio existem evidências do efeito benéfico da aplicação foliar de micronutrientes em certas culturas, como a soja (Rosolem e Boaretto, 1989). Para feijão, segundo Rosolem et al. (1990), o cálcio atua decisivamente no número de flores e vagens abortadas e existe alta correlação negativa entre teor de $\mathrm{Ca}$ na planta e número de flores e vagens abortadas.

Apesar de não ser um nutriente essencial, para o crescimento e desenvolvimento das plantas, diversos estudos têm demonstrado efeitos benéficos do $\mathrm{Si}$ em diversas culturas. Dentre os efeitos se destacam o baixo 
coeficiente de transpiração, com melhor aproveitamento da água, maior teor de clorofila, maior rigidez estrutural dos tecidos com aumento da resistência mecânica das células, folhas mais eretas, área fotossintética maior e maior absorção de $\mathrm{CO}_{2}$. Somam-se a isto, a diminuição do autossombreamento e redução no acamamento, aumento no número de folhas e peso da matéria seca, atraso na senescência e proteção contra estresses abióticos (Adatia e Besford, 1983).

Diante do exposto, o objetivo neste trabalho foi avaliar a eficiência da aplicação de cálcio e silício na proteção de plantas, produção e qualidade de sementes de soja.

\section{MATERIAL E MÉTODOS}

O trabalho foi conduzido na cidade de Três de Maio/ RS, em uma propriedade de um cooperante da Cooperativa Agropecuária Alto Uruguai Ltda (COTRIMAIO) e os testes foram conduzidos no Laboratório Didático de Análise de Sementes (LDAS) da Faculdade de Agronomia Eliseu Maciel (FAEM) da Universidade Federal de Pelotas (UFPel).

Foram utilizadas sementes de soja orgânica (Glycine $\max$ L.) cultivar BR 36 , proveniente da cooperativa COTRIMAIO da safra 2004/2005. A semeadura foi realizada em 27/11/2005 com a densidade de semeadura de 70-80 kg.ha ${ }^{-1}$ de sementes. A colheita foi realizada manualmente em 05/04/2006 com as sementes colhidas a $18 \%$ de umidade, em média. Em seguida, as sementes foram trilhadas utilizando um batedor acoplado a um trator.

O modelo experimental utilizado foi de blocos inteiramente casualizado, com cinco tratamentos (cálcio 40 , cálcio 50 , silício 40 , silício 50 e testemunha) e quatro repetições. Os tratamentos foram comparados pelo teste de Duncan, a $5 \%$ de probabilidade. Para a execução das analises estatísticas foi utilizado o "Sistema de Analise Estatistica para Windows - Winstat" versão 2.0. (Machado, 2000).

As doses utilizadas foram obtidas por meio de testes preliminares onde avaliou-se a quantidade de calda gasta por hectare, a distribuição do produto na planta e a quantidade de resíduo acumulado sobre as folhas. Para obtenção dos tratamentos utilizou-se materiais minerais ricos em cálcio $\left(\mathrm{CaMg}\left(\mathrm{CO}_{3}\right)\right)$ contendo $30 \%$ de Carbonato de Cálcio, aplicado nas doses de 40 e 50 kg.ha-1 ${ }^{-1}$ e Silício proveniente do mineral $\left(\mathrm{AL}_{2} \mathrm{O}_{3} 2 \mathrm{SiO}_{2} 2 \mathrm{H}_{2} \mathrm{O}\right)$ com $77,9 \%$ de Dióxido de Silício, nas doses de 40 e 50 kg.ha-1, constituindo os seguintes tratamentos: cálcio 40, cálcio 50, silício 40, silício 50 e testemunha. Para todos os tratamentos o volume de calda utilizado foi de $200 \mathrm{~L} / \mathrm{ha}^{-1}$.

A aplicação dos tratamentos foi realizada com pulverizadores manuais, costais, nos seguintes períodos: 18 dias após a emergência, 50 dias após a emergência (floração) e 100 dias após a emergência (enchimento de grão).

Para a instalação do experimento utilizou-se uma área total de $360 \mathrm{~m}^{2}$, divididos em seis blocos, sendo cada parcela com dimensionamento de $5 \mathrm{~m}$ de comprimento e 2,40 m de largura (seis linhas). Para a avaliação descartouse as linhas de bordadura, utilizando-se apenas as quatro linhas centrais.

As avaliações de campo foram realizadas na propriedade do cooperante da cooperativa COTRIMAIO, onde durante todo o período houve um constante monitoramento de pragas e doenças. As variáveis dos componentes de produção foram: Número de vagens por planta - obtido pela coleta de trinta plantas colhidas ao acaso, nas quatro linhas centrais da parcela. Número de sementes por vagem - obtido pela separação das vagens com zero, uma, duas e três sementes por vagem. Produtividade - a produtividade média por planta foi determinada nas trinta plantas colhidas ao acaso, dentro de cada parcela, nas seis repetições de cada tratamento. Rendimento de grãos - foi determinado pela colheita das plantas presentes em uma área útil de $9 \mathrm{~m}^{2}$, constituído pelas quatro linhas centrais das parcelas, em uma extensão de cinco metros. As sementes obtidas foram pesadas e determinados o grau de umidade e o peso de mil sementes, segundo metodologia descrita nas Regras para Análise de Sementes (Brasil, 1992). O peso final foi corrigido para $13 \%$ de umidade.

A qualidade fisiológica foi determinada pelos seguintes testes: germinação - foram utilizadas 200 sementes de soja (quatro repetições de 50 sementes). Semeadas sob três folhas de papel toalha previamente umedecido com água destilada na proporção de 2,5 vezes o peso do papel. Os rolos foram colocados no germinador a uma temperatura de $25^{\circ} \mathrm{C} \pm 2{ }^{\circ} \mathrm{C}$, sendo as contagens realizadas aos 5 e 8 dias após a semeadura. A apresentação dos resultados feita pela média aritmética das quatro repetições, em números porcentuais inteiros (Brasil, 1992). Primeira contagem de germinação conduzido juntamente com o teste de germinação, com realização de contagem aos cinco dias após a instalação do teste (Brasil, 1992), sendo os resultados expressos em porcentagem de germinação. Teste de frio - foram 
distribuídas uniformemente quatro repetições de 50 sementes em duas folhas de papel toalha, previamente umedecido com água destilada na proporção de 2,5 vezes o peso do papel seco. Em seguida, foram colocadas outras duas folhas de papel toalha sobre as sementes. Os rolos foram colocados em sacos plásticos fechados, permanecendo por cinco dias no refrigerador a $10{ }^{\circ} \mathrm{C}$. Após, foram colocados no germinador a uma temperatura de $25{ }^{\circ} \mathrm{C} \pm 2{ }^{\circ} \mathrm{C}$ e a contagem realizada no quinto dia, quando se retiraram apenas as plântulas consideradas normais. A apresentação dos resultados foi feita pela média aritmética das quatro repetições, em números percentuais inteiros (Barros et al., 1999). Condutividade elétrica - para esse teste utilizou-se quatro repetições de 25 sementes, provenientes da porção de sementes fisicamente puras. As sementes foram pesadas e colocadas em copos plásticos contendo $75 \mathrm{~mL}$ de água deionizada, mantidas a $20{ }^{\circ} \mathrm{C}$ por 24 horas. A leitura foi determinada através da utilização do aparelho condutivímetro DIGIMED modelo DM-31, sendo o valor obtido, dividido pelo peso das sementes e os resultados expressos em $\mu$ mhos. g $^{-1}$ de semente de acordo com Vieira e Krzyzanowski, (1999).

Teste de envelhecimento acelerado - as sementes foram postas em caixas "gerbox", sobre uma tela, com $40 \mathrm{~mL}$ de água destilada. Após foram levadas para uma câmara BOD a aproximadamente $42{ }^{\circ} \mathrm{C}$ onde ficaram por $72 \mathrm{~h}$. Completado este período, retirou-se o material da BOD e montaram-se quatro repetições de 50 sementes em papel toalha. Em seguida, foram levadas para um germinador por um período de cinco dias onde então foi realizada a contagem final (Marcos Filho, 1999).

\section{RESULTADOS E DISCUSSÃO}

Os resultados do teste de germinação (Tabela 1) mostram que houve efeito positivo para as duas doses de silício e para o cálcio a resposta só foi observada na dose mais alta, quando comparados com o tratamento de cálcio na dose menor e a testemunha. Isso pode ter ocorrido em função de uma melhor proteção da planta, quando submetida a estes tratamentos, ou seja, a planta recebeu uma dose mais uniforme do produto, formando um filme de partículas bem distribuídas sobre a mesma, tornando-a mais resistente ao ataque de pragas e doenças. Por consequência, houve melhor condição de nutrição da planta, com formação de uma semente mais resistente, reduzindo a deterioração, o que foi confirmado pelo teste de germinação.

TABELA 1. Teste de germinação (TG), primeira contagem de germinação (PCG), condutividade elétrica (CE), teste de frio (TF) e envelhecimento acelerado (EA).

\begin{tabular}{cccccl}
\hline Tratamentos & TG $(\%)$ & PCG $(\%)$ & CE $($ umhos/cm/g) & T F $(\%)$ & E.A (\%) \\
\hline Testemunha & $81 \mathrm{~b}$ & $72 \mathrm{~b}$ & $87,09 \mathrm{~b}$ & $27 \mathrm{~b}$ & $67 \mathrm{ab}$ \\
1-Cálcio 40 & $79 \mathrm{~b}$ & $71 \mathrm{~b}$ & $83,27 \mathrm{~b}$ & $16 \mathrm{c}$ & $59 \mathrm{c}$ \\
2-Silí́cio 40 & $88 \mathrm{a}$ & $81 \mathrm{a}$ & $71,37 \mathrm{a}$ & $31 \mathrm{~b}$ & $64 \mathrm{bc}$ \\
3-Cálcio 50 & $87 \mathrm{a}$ & $81 \mathrm{a}$ & $72,98 \mathrm{a}$ & $47 \mathrm{a}$ & $68 \mathrm{ab}$ \\
4-Silí́cio 50 & $88 \mathrm{a}$ & $82 \mathrm{a}$ & $69,25 \mathrm{a}$ & $30 \mathrm{~b}$ & $74 \mathrm{a}$ \\
\hline CV $(\%)$ & 4,29 & 4,81 & 5,81 & 23,48 & 8,24
\end{tabular}

*Médias seguidas pela mesma letra na coluna não diferem entre si pelo teste de Duncan a 5\% de probabilidade.

Esses resultados concordam com Rosolem et al. (1990), que verificaram melhoria na qualidade fisiológica das sementes do feijoeiro em função das doses de $\mathrm{Ca}$ aplicado.

A adubação foliar tem sido recomendada para aumentar ou manter a concentração de nutrientes nas folhas, no período de enchimento de grãos, porque nessa fase, a absorção de nutrientes pelas raízes é praticamente nula (Garcia e Hanway, 1976). Assim, pode-se através desta prática aumentar o conteúdo de nutrientes na planta e o metabolismo formador de estruturas reprodutivas promovendo assim aumento na produtividade.

Os resultados do teste de primeira contagem de germinação (Tabela1) utilizados para avaliar o vigor das sementes apresentaram resultados similares ao teste de germinação, ou seja, os tratamentos silício 40 , silício 50 e cálcio 40, não apresentaram diferença significativa entre si, mas, apresentaram diferença quando comparados com a testemunha e o tratamento cálcio 40. Esse resultado reforça a ideia de que as doses de silício e a dose maior de cálcio 
formaram uma melhor distribuição sobre as plantas, uma maior proteção às mesmas, maior resistência ao ataque de pragas e doenças e, maior vigor, exceto para os tratamentos cálcio 40 (talvez por apresentar uma má distribuição na planta, não formando uma cobertura adequada) e testemunha.

Os valores do teste de condutividade elétrica aumentaram significativamente para o tratamento cálcio 40 e testemunha, mostrando que os demais tratamentos propiciaram uma maior integridade das membranas o que diminuiu a quantidade de íons presentes na água de embebição, diminuindo a degradação das enzimas. Esses resultados apresentam similaridade aos obtidos por Dayanandam et al., (1983) que, além do efeito na transpiração, a deposição de sílica na parede das células torna a planta mais resistente à ação de fungos e insetos. Isso ocorre pela associação da sílica com constituintes da parede celular, tornando-as menos acessíveis às enzimas de degradação.

Durante o período em que foram realizados os tratamentos, não foram observados ataques severos de pragas, tampouco foi observado foco de doenças para todos os tratamentos. No entanto, Lopes (2006) constatou que o silício pode estimular o crescimento e a produção vegetal por meio de várias ações indiretas. Dentre essas ações, o autor cita a diminuição do autossombreamento, deixando as folhas mais eretas, o decréscimo na suscetibilidade ao acamamento, a maior rigidez estrutural dos tecidos, a proteção contra estresses abióticos, como a redução da toxidez de $\mathrm{Al}, \mathrm{Mn}$, Fe e Na, a diminuição na incidência de patógenos e o aumento na proteção contra herbívoros, incluindo os insetos fitófagos.

Para o teste de frio, o tratamento cálcio 50 apresentou diferença quando comparado aos demais tratamentos, com maior germinação quando exposto em condições adversas. Já o envelhecimento acelerado mostrou que o tratamento silício 50 foi superior aos demais, apresentando 74\% de germinação (Tabela 1), indicando que doses maiores de cálcio e silício promovem melhoria na qualidade fisiológica das sementes.

O filme de partículas formado pela deposição de cálcio e silício fornece a planta uma camada branca e fina que confere proteção à mesma, tornando-a não atrativa aos insetos e pragas e, ao mesmo tempo, agindo como repelente no controle dos mesmos. Para algumas doenças, a prevenção ocorre devido às mesmas necessitarem de calor e umidade e, dessa maneira, criando barreiras e impedindo que a água fique aderida na folha, evitando que muitos fungos e patógenos instalem-se nas mesmas.

Para o rendimento de grão (Tabela 2), verificou-se que a testemunha obteve produtividade superior a todos os demais tratamentos. Também pode-se constatar que o peso de mil sementes da testemunha foi superior a todos os demais tratamentos, mostrando que nesta situação as sementes produzidas foram maiores o que ocasionou em um maior rendimento de grãos por hectare.

TABELA 2. Rendimento de grãos (RG), produtividade por planta (PP), número de vagens por planta (NVP), número de vagens com zero (NV), número de vagens com uma, duas e três sementes e, massa de mil sementes (MMS).

\begin{tabular}{lcccccccc}
\hline \multirow{2}{*}{ Tratamentos } & \multirow{2}{*}{ RG(t/ha) } & \multirow{2}{*}{ PP $(\mathrm{g})$} & \multirow{2}{*}{ NVP } & \multicolumn{9}{c}{ NV } & \multirow{2}{*}{ MMS (g) } \\
\cline { 6 - 7 } Testemunha & $3,1 \mathrm{a}$ & $14,4 \mathrm{a}$ & $41 \mathrm{a}$ & $0,4 \mathrm{a}$ & $15 \mathrm{a}$ & $22 \mathrm{a}$ & $3 \mathrm{~b}$ & $199 \mathrm{a}$ \\
1-Cálcio 40 & $2,5 \mathrm{~b}$ & $13,8 \mathrm{a}$ & $40 \mathrm{a}$ & $0,3 \mathrm{~b}$ & $14 \mathrm{ab}$ & $22 \mathrm{a}$ & $3 \mathrm{~b}$ & $194 \mathrm{~b}$ \\
2-Silício 40 & $2,6 \mathrm{~b}$ & $13,9 \mathrm{a}$ & $40 \mathrm{a}$ & $0,2 \mathrm{~b}$ & $12 \mathrm{~b}$ & $23 \mathrm{a}$ & $4 \mathrm{~b}$ & $183 \mathrm{~d}$ \\
3-Cálcio 50 & $2,6 \mathrm{~b}$ & $14,0 \mathrm{a}$ & $38 \mathrm{a}$ & $0,2 \mathrm{bc}$ & $12 \mathrm{~b}$ & $22 \mathrm{a}$ & $4 \mathrm{~b}$ & $190 \mathrm{c}$ \\
4-Silício 50 & $2,7 \mathrm{~b}$ & $14,1 \mathrm{a}$ & $43 \mathrm{a}$ & $0,1 \mathrm{c}$ & $14 \mathrm{ab}$ & $24 \mathrm{a}$ & $5 \mathrm{a}$ & $186 \mathrm{~cd}$ \\
\hline CV $(\%)$ & 9,02 & 11,41 & 10,89 & 39,46 & 12,2 & 13,14 & 21,04 & 1,94 \\
\hline
\end{tabular}

*Médias seguidas pela mesma letra na coluna não diferem entre si pelo teste de Duncan a 5\% de probabilidade.

Não foram detectados respostas da soja a doses de Ca e $\mathrm{Si}$, aplicados via foliar durante o ciclo da cultura, em termos de rendimento de grãos e, número de vagens por planta, tampouco o estado nutricional da planta foi modificado. 
Da mesma maneira, para Ben et al. (1993), não houve efeito benéfico dos fertilizantes foliares contendo $\mathrm{Ca}$ a $10 \%$, sozinho, ou junto com outros micronutrientes sobre o rendimento de soja. Contrários a esses resultados, Rosolem et al. (1990), afirma que existe alta correlação negativa entre teor de $\mathrm{Ca}$ na planta e número de flores e vagens abortadas o que explica também o resultado positivo do Ca no peso de sementes por planta.

$\mathrm{Na}$ produtividade por planta (Tabela 2), não foram observadas diferenças estatísticas entre os tratamentos, apenas uma tendência de maior produtividade por planta para a testemunha. Contudo, os resultados observados são contrários aos aumentos de produtividade, observados pela aplicação de silício em cana-de-açúcar (Korndörfer et al., 2002) e em arroz (Carvalho-Pupatto et al., 2004).

Nas variáveis, rendimento de grão e massa de mil sementes, onde a testemunha foi superior aos demais tratamentos, tais resultados podem ter sido influenciados pela não cobertura do filme de partículas, favorecendo a taxa fotossintética, discordando das características citadas por Glenn et al. (2005), que diz que o uso do filme de partículas não afeta a fotossíntese, devido a sua natureza porosa. Por outro lado, o uso do filme daria a condição de proteção, impedindo ou repelindo o aparecimento de doenças e pragas, o que visualmente pode ser observado em termos de sanidade, na área experimental.

No presente estudo, a massa de 1000 sementes foi significativamente inferior para todos os tratamentos, quando comparada à testemunha, indicando que a aplicação não proporcionou maior acúmulo de matéria seca.

Quanto a qualidade fisiológica das sementes, de modo geral observou-se que houve aumento nos percentuas de germinação e vigor, quando comparados com a testemunha.

Ao produtor de grãos, esses tratamentos não interessam, pois a perda percentual, considerando-se os resultados obtidos, poderia atingir entre $10 \%$ e $15 \%$. Pode-se dizer que esse tipo de tratamento poderia ser indicado para áreas de produção de sementes, onde se visa qualidade e não quantidade.

\section{CONCLUSÃO}

Plantas de soja tratadas com cálcio e silício produzem sementes de melhor qualidade fisiológica.

Os tratamentos com aplicação de cálcio e silício reduzem o rendimento de sementes por unidade de área.

\section{REFERÊNCIAS}

ADATIA, M.H.; BESFORD, R.T. The effect of silicon on cucumber plants grown in recirculating nutrient solution. Annali Botanica, v.58, n.3, p.343-351, 1983.

AMBIENTEBRASIL. Agricultura Orgânica. Disponível em: $<$ http://ambientebrasil.com.br $>$. Acesso em: 28 de jul. 2005.

BARROS, A.S. do R.; DIAS, M.C.L.L.; CÍCERO, S.M.; KRZYZANOWSKI, F.C. Testes de frio. In: KRZYZANOWSKI, F.C.; VIEIRA, R.D.; FRANÇA NETO, J.B. Vigor de sementes: conceitos e testes. Londrina: ABRATES. cap. 5, p.5-1 a 5-15, 1999.

BEN, J.R.; POTTKER, D.; MEDEIROS, L.A. Avaliação de fertilizantes foliares para a soja. In: REUNIÃO DE PESQUISA DE SOJA DA REGIÃO SUL, 21, 1993. Santa Rosa. Soja: Resultados de Pesquisa 1992- 1993. Santa Rosa: Cooperativa Mista Missões. 199p. (EMBRAPACNPT. Documentos, 9).

BRASIL. Ministério da Agricultura e Reforma Agrária. Secretaria Nacional de Defesa Agropecuária. Departamento Nacional de Produção Vegetal. Coordenação de Laboratório Vegetal. Regras para Análise de Sementes. Brasília, DF, 1992.365p.

BRASIL. Ministério da Agricultura, Pecuária e Abastecimento Gabinete do Ministro. Instrução Normativa $\mathrm{n}^{\circ}$ 7, de 17 de maio de 1999. Dispõe sobre normas para a produção de produtos orgânicos vegetais e animais. Publicado no Diário Oficial da União, Poder Executivo, Brasília, DF, 15 de outubro de 1999.

CARVALHO-PUPATTO, J.G.; BULL, L.T.; CRUSCIOL, C.A.C. Atributos químicos do solo, crescimento radicular e produtividade do arroz de acordo com a aplicação de escórias. Pesquisa Agropecuária Brasileira, v.39, n.12, p.1213-1218, 2004.

CONAB Companhia Nacional de Abastecimento. Disponível em: <http://www.conab.gov.br/OlalaCMS/ uploads/arquivos/969898a66ca1 ceede424d5853d3f8543. pdf $>$ Acesso em: 25 jul. 2010.

DAYANADAM, P.; KAUFMAN, P.B.; FRANKLIN, C.L. Detection of silica in plants. American Journal of Botany, v.70, p.1079-1084, 1983.

EMBRESA BRASILEIRA DE PESQUISA AGROPECUARIA. Soja na Alimentação. Embrapa Soja, 2002. Disponível em: <http://cnpso.embrapa.Br/soja alimentação/>. Acesso em: 28 jul. 2005.

GARCIA, L.R.; HANWAY, J.J. Foliar fertilization of 
soybeans during the seed-filling period. Agronomy Journal, v.4, n.68, p.763 - 769, 1976.

GLENN, D.M.; PUTERKA, G.; VANDERSWET, T.; BYERS, R. E.; FELDHAKE, C. Hydrophobic Particle Films: a new paradigm for suppression of arthropod pests and plant diseases. Disponível em: $<\mathrm{http}$;//afrsweb.usda. gov/pdf"s/hydrophobic>. Acesso em: 20 jul. 2005.

KORNDÖRFER, G.H.; PEREIRA, H.S.; CAMARGO, M.S. Papel do silício na produção de cana-de-açúcar. STAB, v.21, n.2, p.34-37 2002.

LOPES, F.C. de A. Efeito de Fontes de Silício no Controle de Fusarium oxysporum $f$. Sp. Lycopersici em Tomateiro (Lycopersicum esculentum. Mill.). 2006. 78f. Dissertação (Mestrado) - Universidade Federal de Lavras, 2006.

MACHADO, A. Programa de Análise Estatistica - Winstat 2, 2000. Disponível em: www.ufpel.tche. $\mathrm{br} / \sim \operatorname{amachado} /$ winstatsoftware $>$. Acesso em: 15 jun. 2006.

MARCOS FILHO, J. Teste de envelhecimento acelerado. In: KRZYZANOWSKI, F.C.; VIEIRA, R.D.; FRANÇA NETO, J.B. Vigor de sementes: conceitos e testes.
Londrina: ABRATES. cap. 3, p.3-1 a 3-24, 1999.

PLANETA ORGÂNICO. Soja orgânica. o tesouro da produção nacional. Disponível em: http://www. planetaorganico.com.br/sojaorg.htm. Acesso em: 25 de jul. 2010.

PUTERKA, G. Appalachian Fruit Research Station. Disponível em: <http;//afrsweb.usda.gov/gputerka.htm>. Acesso em: 20 jul. 2005.

ROSOLEM, C.A.; BOARETTO, A.E. A adubação foliar em soja. In: BOARETTO, A.E.; ROSOLEM, C.A. (Ed.). Adubação foliar. Campinas, SP: Fundação Cargill. 1989. 500 p.

ROSOLEM, C.A.; BOARETTO, A.E.; NAKAGAWA, J. Adubação foliar do feijoeiro. VIII. Fontes e doses de cálcio. Científica, v.18, p.81-86, 1990.

VIEIRA, R.D.; KRZYZANOWSKI, F.C. Teste de condutividade elétrica. In: KRZYZANOWSKI, F.C.; VIEIRA, R.D.; FRANÇA NETO, J.B. Vigor de sementes: conceitos e testes. Londrina: ABRATES. cap. 3, p.3-1 a 3-24, 1999. 